\title{
Use of a semi-dry dot-blot for rapid detection of lymph node metastasis
}

Hiroshi Hirakawa·

Department of Tumor and Diagnostic Pathology, Atomic Bomb Disease Institute, Nagasaki University Graduate School of Biomedical Sciences, 1-12-4 Sakamoto, Nagasaki 852-8523, Japan

•Corresponding author. Tel.: +81 95819 7107;

fax: +81958197108.

E-mail address: h-hira@nagasaki-u.ac.jp.

Kenichiro Shibata

Division of Surgical Oncology, Department of Translational Medical Sciences, Nagasaki University Graduate School of Biomedical Sciences, 1-7-1 Sakamoto, Nagasaki 852-8501, Japan

Etsuko Ohzono

Department of Tumor and Diagnostic Pathology, Atomic Bomb Disease Institute, Nagasaki University Graduate School of Biomedical Sciences, 1-12-4 Sakamoto, Nagasaki 852-8523, Japan

Dear Editor,

To match sophisticated medical technology and diversified patient requirements, it is essential to use novel methods for intraoperative diagnosis. For example, sentinel lymph node biopsy has become a common surgical procedure for treating breast cancer [1]. Further, touch imprint cytology and frozen-section pathological diagnosis are commonly used for the rapid detection of tumor deposits. However, technical expertise is required for processing frozen sections, and it is vital that an experienced pathologist or cytologist examines the frozen sections. Moreover, intraoperative diagnosis cannot be conducted at some institutions because of the lack of pathology specialists. Additionally, many cases of operations for cancers are currently performed without confirming lymph node metastasis.

We describe a facile, quick, and cost-effective method for dot-blot analysis (Fig. 1). The time taken was approximately $20 \mathrm{~min}$ (the antibodies and chromogen used for detection and descriptions of the procedures are shown in Table 1). By using the MCF-7 human breast cancer cell line or breast cancer tissue homogenate, it is possible to detect at a minimum 20 cancer cells per dot or protein at $0.01 \mathrm{mg} / \mathrm{ml}$ with our protocol. We tested this protocol for 20 lymph node samples (5 nodes with metastasis, 15 nodes without metastasis) obtained from 11 patients. Two patients with micrometastasis (diameter of metastasis, $2 \mathrm{~mm}$ ) were 
included. Here, we compared the sensitivity and specificity (100\%; 5/5 and 15/15, respectively) on the basis of the pathological diagnosis. PCR is another efficient method that uses molecular markers for detecting lymph node metastasis $[2,3]$. As compared to PCR, our method neither requires a special machine such as the thermal cycler nor specially trained technical operators. Further, the use of a chromogen for analyzing results does not require special skills. We considered that our method can be used at hospital bedsides or in operation rooms. For clinical use, we considered that the sensitivity and specificity cannot be determined until accumulation of more than 100 cases. Our method is simple, fast, and cost-effective for identifying lymph node metastases. The accumulation of cases is insufficient, but this method is expected to be used for the detection of sentinel lymph node metastasis or peritoneal cancer cell dissemination. Currently, we are examining the efficacy of this method for analyzing clinical specimens.

\section{References}

[1] Veronesi U, Paganelli G, Viale G, Luini A, Zurrida S, Galimberti V, et al. A randomized comparison of sentinel-node biopsy with routine axillary dissection in breast cancer. $\mathrm{N}$ Engl J Med 2003;349:546-53.

[2] Visser M, Jiwa M, Horstman A, Brink AA, Pol RP, van Diest P, et al. Intra-operative rapid diagnostic method based on CK19 mRNA expression for the detection of lymph node metastases in breast cancer. Int J Cancer 2008;122(11):2562-7.

[3] Schem C, Maass N, Bauerschlag DO, Carstensen MH, Löning T, Roder C, et al. Onestep nucleic acid amplification-a molecular method for the detection of lymph node metastases in breast cancer patients; results of the German study group. Virchows Arch 2009;454(2):20310. 

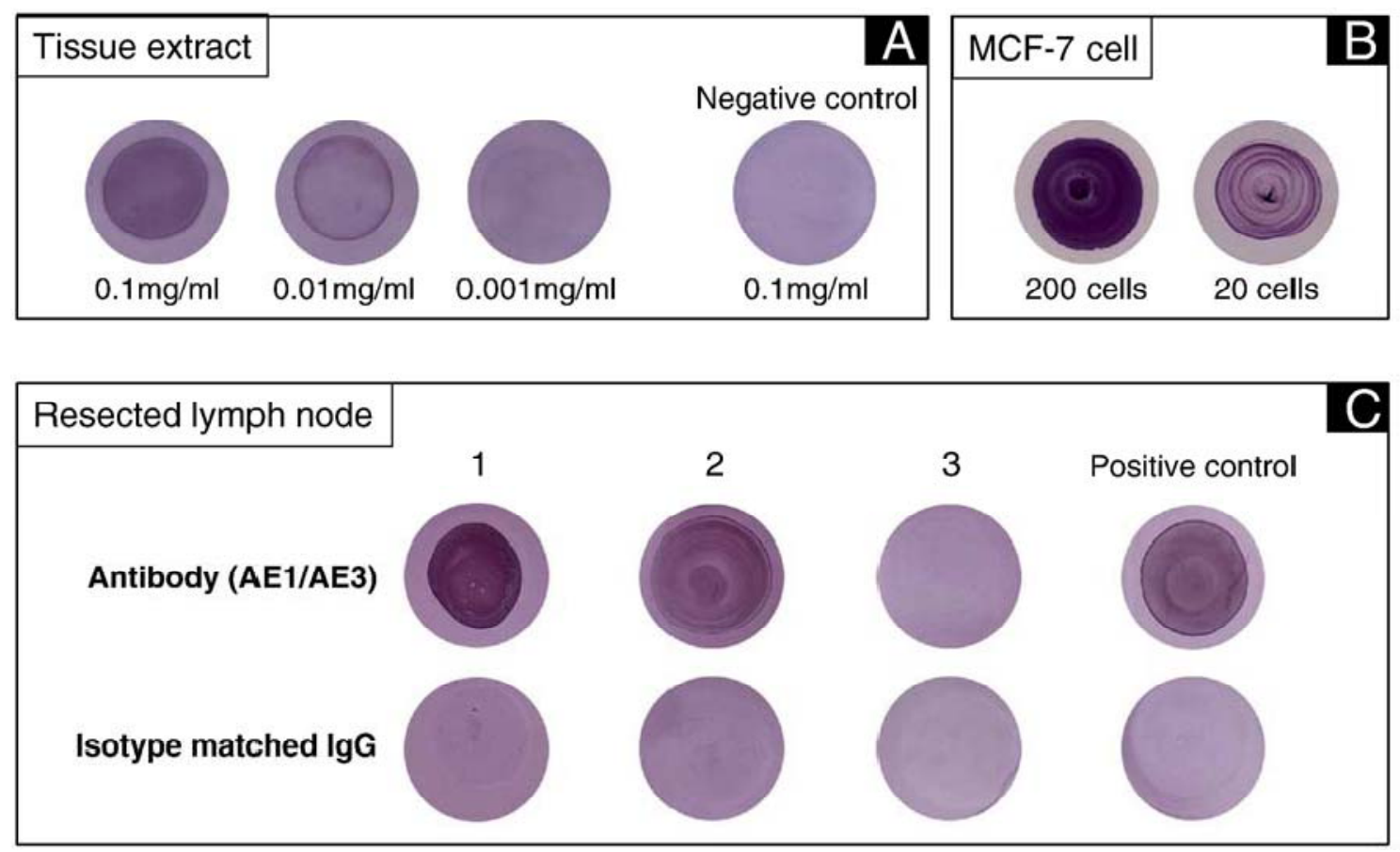

Fig. 1. Dot-blot assay. (A) Breast cancer tissue extract. The concentrations of total protein for detection of AE1/AE3 are $0.1 \mathrm{mg} / \mathrm{ml}, 0.01 \mathrm{mg} / \mathrm{ml}$ and $0.001 \mathrm{mg} / \mathrm{ml}$ from the left. The concentration of total protein for negative control (isotype matched lgG) is $0.1 \mathrm{mg} / \mathrm{ml}$. (B) MCF-7 cells. The total cell numbers are 200/dot and 20/dot from the left. (C) 1-3: resected lymph node. 1 and 2: metastasized lymph node, 3:non-metastasized lymph node and positive control (breast cancer tissue extract). Upper column: AE1/AE3. Lower column: isotype matched IgG. 


\section{Table 1}

\section{Procedure of semi-dry dot-blot for rapid detection.}

Antibodies

Primary antibody: anti-pancytokeratin (AE1/AE3) (Nichirei, Tokyo, Japan)

Secondary antibody: Peroxidase-coupled anti-mouse IgG (ImmPRESS anti-mouse IgG) (Vector laboratories, Burlingame, CA)

\section{Chromogen}

Chromogen: VIP substrate kit (Vector Laboratories)

Procedures

(A) Sample preparation

1. Cut the resected lymph nodes with knives.

2. Wash the sectioned surface with $2 \mathrm{ml}$ of phosphate-buffered saline (PBS).

3. Put the contents in a microtube, centrifuge in a microtube centrifuge for $1 \mathrm{~min}$, and discard the supernatant.

4. Collect the cell pellet formed and lyse it with lysis buffer $(20 \mu \mathrm{l} ; 50 \mathrm{mmol} / \mathrm{l}$ Tris- $\mathrm{Cl}[\mathrm{pH} 7.6]$, $150 \mathrm{mmol} / \mathrm{l} \mathrm{NaCl}, 0.1 \%$ Nonidet P-40) for 3 min at room temperature.

5. Filter connective tissue and adipose tissue through a spin column filter (pore size; $\sim 10$ $\mu \mathrm{m})$.

(B) Preparation of the absorption paper for semi-dry blot

1. Place the absorption paper (Bio-Rad Laboratories, Hercules, CA) into wash buffer (PBS-T: 0.05\% Tween 20 in PBS) for 2 min.

2. Remove the absorption paper and thoroughly drain off the wash buffer.

(C) Dot-blot analysis (each reaction is carried out on a polyethersulphone membrane on the absorption paper)

1. Spot the sample $(2 \mu \mathrm{l})$ onto the polyethersulphone membrane (UltraBind US450, Pall Corp., Port Washington, NY).

2. Dry the membrane for 3 min at room temperature.

3. Place the membrane on the absorption paper.

4. Incubate the membrane with blocking solution ( $20 \mu \mathrm{l} ; 0.05 \%$ skimmed milk in PBS-T) for 5 S. 
5. Wait for $30 \mathrm{~s}$ until excess water is absorbed by the absorption paper.

6. Incubate the membrane with primary antibody $(5 \mu \mathrm{l})$ for $3 \mathrm{~min}$ at room temperature.

7. Wash the membrane once with PBS-T (20 $\mu$ l).

8. Wait for $30 \mathrm{~s}$ until excess water is absorbed by the absorption paper.

9. Incubate the membrane with secondary antibody $(5 \mu \mathrm{l})$ conjugated with horseradish peroxidase (HRP) for 3 min at room temperature.

10. Wash the membrane twice with PBS-T $(20 \mu \mathrm{l})$.

11. Wait for 1 min until excess water is absorbed by the absorption paper.

12. Detect the immunoreaction by using the chromogen (30 $\mu$ lof chromogen, for $2 \mathrm{~min}$, at room temperature). 